\title{
Amiodarone induces cell wall channel formation in yeast Hansenula polymorpha
}

\author{
Tatyana S. Kalebina ${ }^{1 *}$, Sviatoslav S. Sokolov², Irina O. Selyakh³, Darya P. Vanichkina ${ }^{1,4}$ and Fedor F. Severin²
}

\begin{abstract}
The yeast cell wall is constantly remodeled to enable cell growth and division. In this study, we describe a novel type of cell wall modification. We report that the drug amiodarone induces rapid channel formation within the cell wall of the yeast Hansenula polymorpha. Light microscopy shows that shortly after adding amiodarone, spherical structures, which can be stained with DNA binding dyes, form on the cell surface. Electron microphotographs show that amiodarone induces the formation of channels $50-80 \mathrm{~nm}$ in diameter in the cell wall that appear to be filled with intracellular material. Using fluorescent microscopy, we demonstrate MitoTracker-positive DNA-containing structures visibly extruded from the cells through these channels. We speculate that the observed channel formation acts to enable the secretion of mitochondrial material from the cell under stressful conditions, thus enabling adaptive changes to the extracellular environment.
\end{abstract}

Keywords: Programmed cell death, Yeast cell wall, Amiodarone

\section{Background}

The yeast cell wall $(\mathrm{CW})$ is a dynamic, multifunctional, and physiologically active organelle that is responsible for interactions between the microorganism and its environment (Lesage and Bussey 2006; Orlean 2012; Teparić and Mrsa 2013).

The major components of the $\mathrm{CW}$ are glucan, mannoproteins, and chitin. Glucan consists of $\beta-1,3-$ and $\beta$-1,6-bound glucose residues and is the central structural component (Klis et al. 2002) that forms a rigid network to which other functional molecules, particularly mannoproteins, are covalently bonded. During yeast cell growth and division, the CW is constantly remodeled (Sestak et al. 2004). The remodeling process is carried out by glucan remodeling enzymes and includes hydrolysis of the polysaccharides network and subsequent incorporation of newly synthesized molecules.

Programmed cell death has been extensively studied in yeasts. In particular, it has been shown that the drug amiodarone can induce cell death in Saccharomyces

\footnotetext{
*Correspondence: kalebina@genebee.msu.ru

${ }^{1}$ Department of Molecular Biology, Faculty of Biology, Lomonosov Moscow State University, 1-12 Leninskie Gory, Moscow 119992, Russia Full list of author information is available at the end of the article
}

cerevisiae by triggering a cascade of proapoptotic changes in mitochondria. Amiodarone stimulates respiration and increases energy coupling in mitochondria, and this leads to generation of reactive oxygen species (Pozniakovsky et al. 2005; Sokolov et al. 2006). It is well known that the rigid cell wall is essential for the protection of yeast cells against negative environmental factors. Earlier, it was demonstrated that amiodarone affects a number of genes involved in CW synthesis (Courchesne et al. 2009; Gamarra et al. 2010). Therefore, one can expect that amiodarone would cause certain structural changes in the CW. However, there are no data on morphological changes in the structure of the cell wall of yeast that occur under the influence of amiodarone.

Over the years, we have accumulated significant experience in treatment of $S$. cerevisiae cells with various toxic, especially pro-oxidant agents, and we have never seen membranous blebs being extruded by the cell-the phenomenon described in this work. Interestingly, similar changes were reported for diamide-treated S. cerevisiae cells (de Souza Pereira and Geibel 1999). Using atomicforce microscopy, they revealed structures in the cell wall that they called "pores". Unfortunately, the data provided by their report seem to be not sufficiently conclusive due to limitations of their technique. Because atomic-force

\section{垈 Springer}

(c) 2015 Kalebina et al. This article is distributed under the terms of the Creative Commons Attribution 4.0 International License (http://creativecommons.org/licenses/by/4.0/), which permits unrestricted use, distribution, and reproduction in any medium, provided you give appropriate credit to the original author(s) and the source, provide a link to the Creative Commons license, and indicate if changes were made. 
microscopy does not allow determining whether the pores span the cell wall, we think that most likely in this case there were thin layers of cell wall material at the bottom of the pores.

Thus, we studied the effect of amiodarone on a similar model organism, the budding obligate aerobe yeast Hansenula polymorpha ${ }^{1}$. We found that high doses of amiodarone (lethal for approximately half of the cells present in the culture) induced dramatic morphological changes in the $H$. polymorpha cell wall leading to formation of channels. After amiodarone treatment, the MitoTracker-positive cellular content of $H$. polymorpha, presumably mitochondria, extruded through these channels.

\section{Results and discussion}

To see the effect of amiodarone on $H$. polymorpha, we treated cells grown in a liquid culture with varying concentrations of the drug and found that amiodarone at $80 \mu \mathrm{M}$ concentration killed approximately $50 \%$ of the cells. Using differential interference contrast (DIC) microscopy, we noticed that after addition of $80 \mu \mathrm{M}$ amiodarone, cells formed cone-shaped protrusions and spherical structures at their surfaces (Fig. 1a, b) after 15 min of incubation with amiodarone. To determine the nature of these structures, we stained them with a number of fluorescent dyes. We found that both propidium iodide (PI) and 6'-diamidino-2-phenylindole (DAPI) (Fig. 1c, d) were accumulated by these spherical structures. Our observations suggested the intriguing possibility that DNA was being transported across the cell wall. We reasoned that dramatic changes must occur in cell wall morphology, and we used transmission electron microscopy (EM) to test this hypothesis. Electron microphotographs revealed that amiodarone triggered a number of structural changes in the cell wall: (1) the wall visibly thickened in an uneven way: (2) the electron-transparent glucan layer (marked G, Fig. 2a, b) thickened up to $200-400 \mathrm{~nm}, 2-4$ times thicker than in the control; (3) the electron-dense external layer, supposedly of mannoprotein nature (Fig. 2b), becomes less dense and seemed thinner compared to a glucan layer (Fig. 2a-c). Crucially, during this process the cell did not change its size significantly (Fig. 1a, b). We also noticed that unusual structures were forming within the cell walls, which we called channels, because they spanned the cell wall (Fig. 2c-e). We estimate the diameter of

\footnotetext{
${ }^{1}$ Hansenula was described to include different species that are included in the teleomorph genus Ogataea (Yamada et al. 1994). Because M14 and u23m25 strains ascend to H. polymorpha CBS 4732 strain (Agaphonov et al. 2005), they should be named O. polymorpha (sensu stricto) (Suh and Zhou 2010), but $H$. polymorpha is a more common name and is used in this report.
}

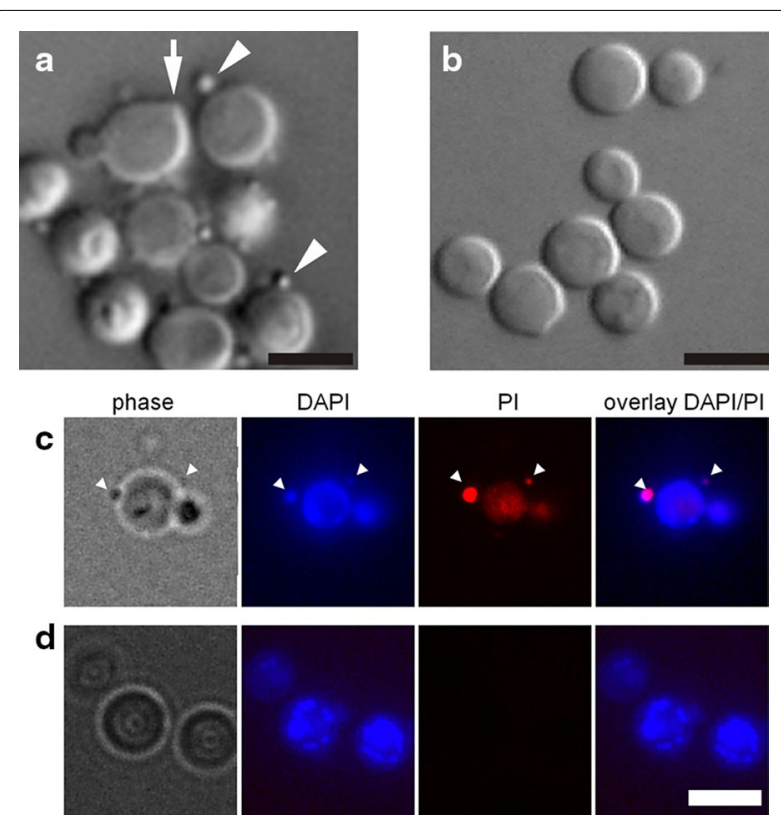

Fig. 1 Hansenula polymorpha cells treated with amiodarone $(\mathbf{a}, \mathbf{c})$ or untreated cells (b, d). $\mathbf{a}, \mathbf{b}$-differential interference contrast (DIC) microscopy, $\mathbf{c}, \mathbf{d}$-combined phase and fluorescence microscopy images of cells after propidium iodide and DAPI treatment. The arrow marks a cone-shaped protuberance (a); arrowheads mark spherical structures at the surface $(\mathbf{a}, \mathbf{c})$. Bar length $5 \mu \mathrm{m}$

the channels to be $50-80 \mathrm{~nm}$. Interestingly, intracellular material appeared to be transferred across these channels (Fig. 2c-e).

The electron microscopy study showed that the intracellular material gathered in the proximity of the channels (Fig. 2d) and formed electron-dense regions (Fig. 2d). The images suggest that after passing through the channel, this material accumulated at the cell wall outer surface (Fig. 2d) forming spherical structures. Moreover, the EM images suggest that the channels of neighboring cells might interact with each other to allow the exchange of the intracellular material (Fig. 2e). Such contacts are most likely destroyed in a liquid medium because the flow of the liquid ruptures the contacts.

Our results raise two questions. First, what is the physiological reason for formation of the channels? The fact that the material protruding from them was positively stained by PI and DAPI points to the presence of DNA in this material, suggesting that amiodarone induced extrusion of DNA from the cell through the channels. The origin of those DNA molecules could be either nuclei or mitochondria.

It was suggested by Koren (2006) that stressful conditions might induce gene transfer between yeast cells. $\mathrm{He}$ argued that mixing of the genetic material might 


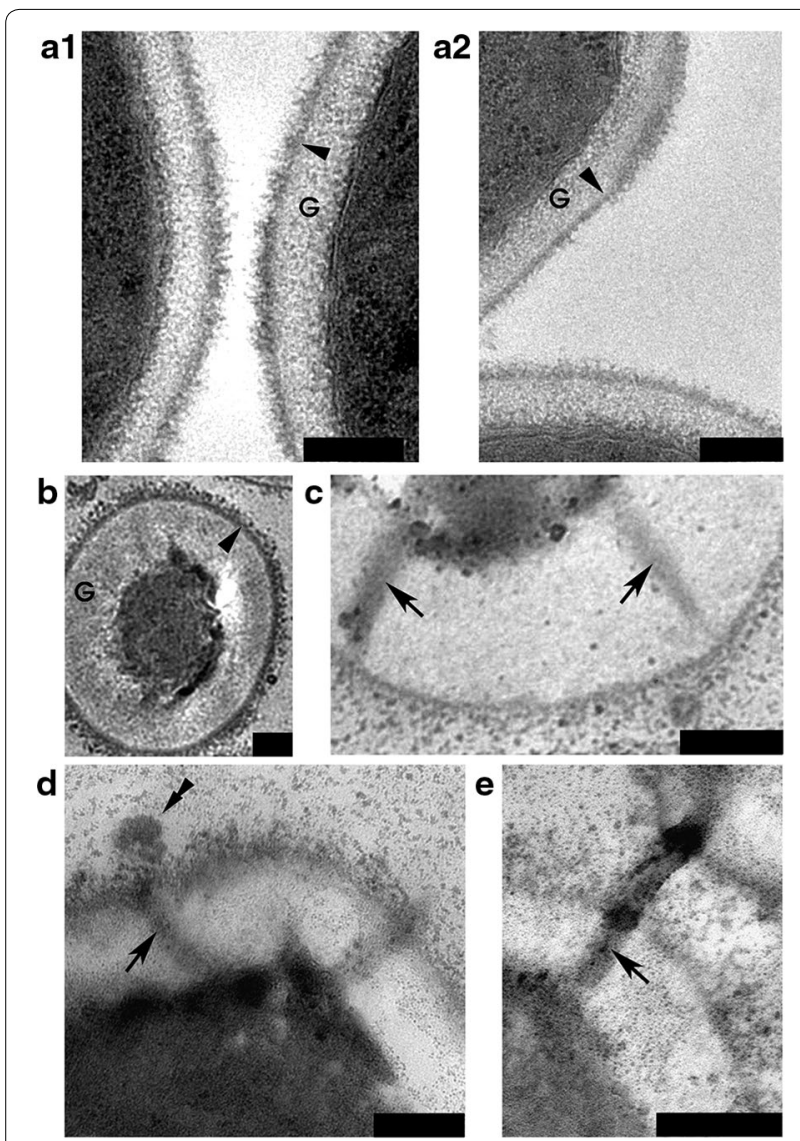

Fig. 2 Electron microphotographs of untreated Hansenula polymorpha cells (a) and cells treated with amiodarone (b-e). Electron-dense channels (black arrow) span the cell wall. G glucan layer, black arrowheads-mannoproteins. Electron-dense areas can be seen where the channels exit the cell (double black arrowheads). Bar length $0.2 \mu \mathrm{m}$

be beneficial to the cell population under severe stress (Koren 2006).

We monitored the transfer of two different auxotrophy markers between cells upon amiodarone treatment. We estimated the frequencies of gene transfer by using colony growth assay on selective media lacking both auxotrophic substances. Equal amounts of m14 (leu2ade2URA3) and u23m25 (leu2ura3ADE2) cells were mixed, and amiodarone was added to the mixture. After $5 \mathrm{~min}$, the cells were centrifuged to facilitate cell-tocell contacts and then incubated for $1 \mathrm{~h}$. The cells were then resuspended and transferred onto YNB plates lacking adenine and uracil. The control cells were treated in the same way but excluding addition of amiodarone. In approximately 50 experiments, it was seen that the control cells did not produce any colonies, while the amiodarone-treated mixtures of the two cell types produced colonies with an estimated frequency of approximately $10^{-9}$ viable colonies per total number of cells in the assay.
This estimate came from the following data: we observed 11 colonies in approximately 50 experiments, and the number of cells in the experiments was in the range of $10^{7}-10^{8}$.

To confirm that the gene transfer was not due to conventional mating, we checked using a FACS assay whether the surviving colonies contained haploid or diploid cells. The cells were haploid, which excludes the possibility that the marker acquisition was due to mating. Seven colonies were analyzed, and all of them appeared to be haploid; two representative FACS profiles are shown (Fig. 3). Therefore, our experimental results are consistent with the idea of transfer of genetic markers between the cells, but the low frequency of the transformation leaves the possibility that the ability to grow was acquired via random mutagenesis.

At the same time, it is known that the formation of mitoptotic bodies and extrusion of mitochondrial material from the cell (mitoptosis) serves as a protection of eucaryotic cells under conditions of mitochondrial stress (Lyamzaev et al. 2008). Thus, it is tempting to suggest that, similar to stressed mammalian cells, in yeasts amiodarone stimulates mitoptosis, and the cells get rid of mitochondria through the channels in the cell wall. We observed MitoTracker-positive structures that were visibly detected as protrusions on the cell surface after amiodarone treatment (Fig. 4). It also can be seen that the MitoTracker staining is more diffuse in the treated cells. This is not surprising: in S. cerevisiae, high concentrations of amiodarone cause major changes in mitochondria: at first, they hyperpolarize them, inducing fragmentation, and later mitochondria depolarize and rupture (Pozniakovsky et al. 2005; Ozhovan et al. 2009). We speculate that the PI- and MitoTracker-stained extracellular material identified as mitochondrion-like particles surrounded by a membrane were indeed mitochondria, and the observed process was mitoptosis.

The second question concerns the mechanism of such a rapid channel formation in the $H$. polymorpha cell wall. It is possible that enzymes with autolytic substrate specificity digest the cell wall to produce the channels. Indeed, yeast cells can make considerable adjustments to the composition and structure of the wall, for example during the cell cycle or in response to environmental conditions such as nutrient and oxygen availability (Smits et al. 1999). These changes are caused by periplasmic or cell wall enzymes, most notably the glucan remodeling enzymes that remodel the $\beta$-glucans-the main constituents of the cell wall (Smits et al. 1999; Cabib et al. 2008). Our data are consistent with results obtained previously (Courchesne et al. 2009). The formation of "canals" was demonstrated after cultivation of the yeast Schwanniomyces occidentalis on hydrocarbons (Dmitriev et al. 


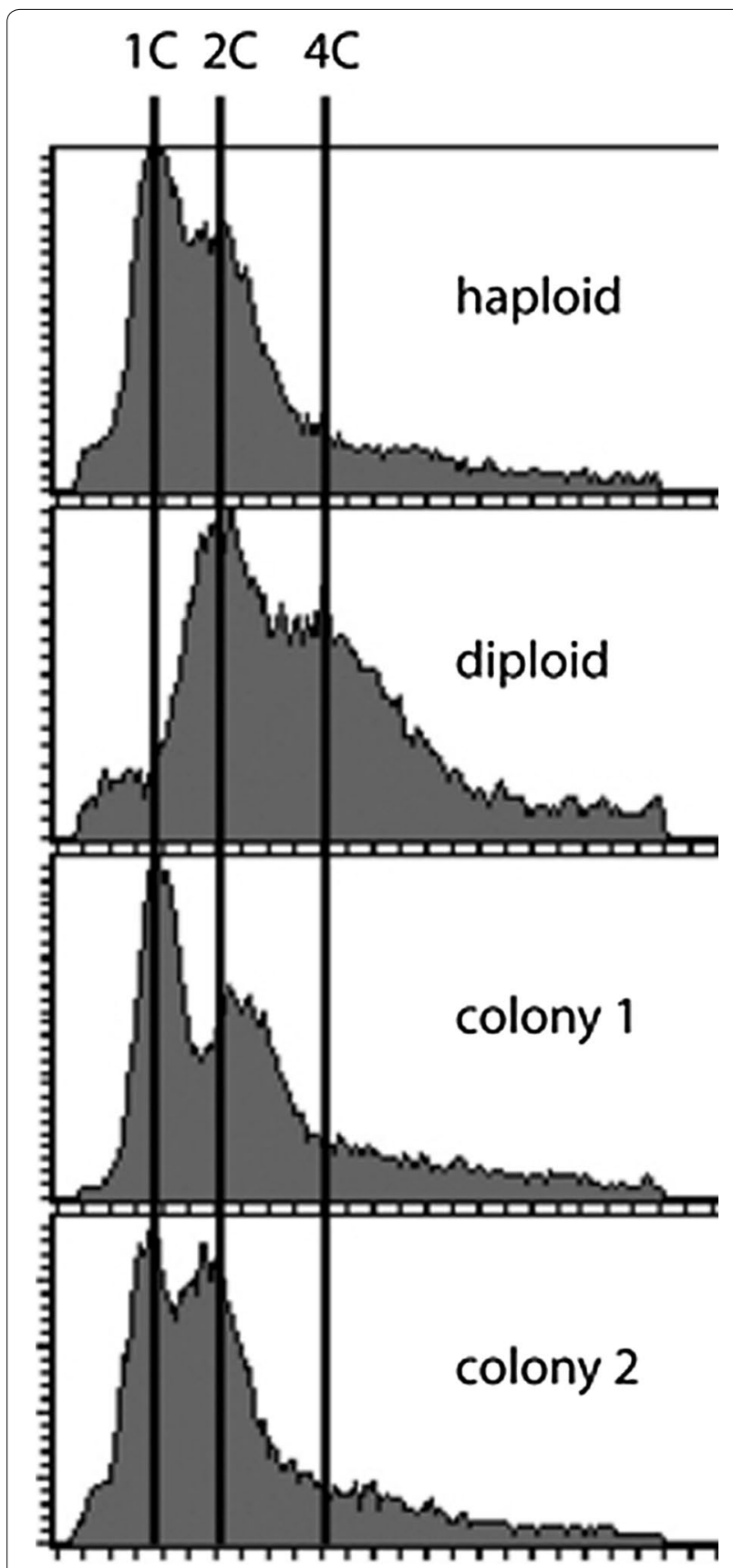

Fig. 3 FACS profiles of DNA content of Hansenula polymorpha haploid and diploid strains and two colonies obtained after amiodarone treatment grown on media without adenine and uracil. Axis X: cellular DNA content. Axis Y: Relative frequency. C1, C2, and C4-DNA content

1980) and was shown to be accompanied by activation of $\beta$-glucosidase, $\beta$-glucanase, and $\alpha$-mannosidaseenzymes capable of degrading cell wall polysaccharides
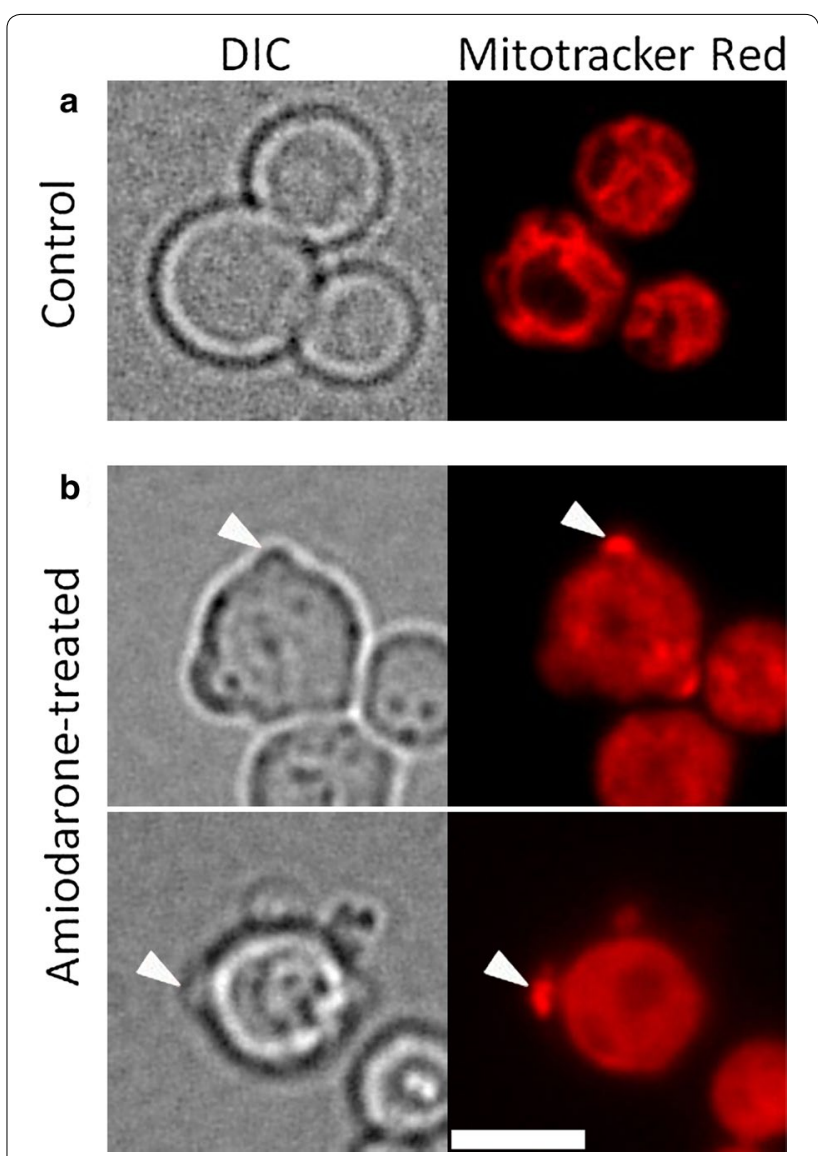

Fig. 4 Untreated Hansenula polymorpha cells (a) or cells treated with amiodarone (b). Left-DIC microscopy; right—fluorescence microscopy images of cells after Mitotracker Red treatment. Arrowheads show a Mitotracker-positive protrusion. All pictures are of the same scale. Bar length $5 \mu \mathrm{m}$

(Dmitriev et al. 1980). Further research is required to determine whether the amiodarone-induced channels that we observed formed due to rapid activation of these autolytic enzymes.

\section{Conclusions}

To summarize, our data and previous observations (Dmitriev et al. 1980; Pozniakovsky et al. 2005; Sokolov et al. 2006; Lyamzaev et al. 2008; Courchesne et al. 2009) are consistent with the idea that the presence of amiodarone in the medium creates harsh conditions for yeast cells, leading to the formation of cell wall channels with the participation of glucan remodeling enzymes that remodel the $\beta$-glucans - the main constituents of the cell wall. The formation of such channels may be accompanied by the extrusion of mitochondrial material from the cell under stressful conditions. 


\section{Methods}

\section{Yeast and growth conditions}

Hansenula polymorpha M14 and u23m25 strains were described previously (Agaphonov et al., 2005). The $H$. polymorpha cells were cultivated at $37{ }^{\circ} \mathrm{C}$ in the complex medium YEPD-1 \% yeast extract, $2 \%$ peptone, $2 \%$ glucose, and $2 \%$ agar when needed. The diploid strain of $H$. polymorpha was obtained by crossing of M14 and $\mathrm{u} 23 \mathrm{~m} 25$ strains.

\section{Treatment of yeast cells with amiodarone and their light microscopy}

Hansenula polymorpha cells were grown in liquid YEPD medium at $37{ }^{\circ} \mathrm{C}$ overnight to the logarithmic phase. Amiodarone was diluted in DMSO, final concentration $0.4 \%$. Half-lethal concentration of amiodarone of $80 \mu \mathrm{M}$ was chosen for the experiments. At this concentration, from 20 to $60 \%$ of the $H$. polymorpha cells survive after $1 \mathrm{~h}$ of incubation, amiodarone at $20 \mu \mathrm{M}$ does not affect, and $40 \mu \mathrm{M}$ slightly reduces $H$. polymorpha cells survival (90-100\% survival). Amiodarone concentration of $120 \mu \mathrm{M}$ causes death of $80 \%$ or more of the $H$. polymorpha cells.

Cells were analyzed after $15 \mathrm{~min}$ of incubation with amiodarone by fluorescence microscopy and by electronmicroscopic analysis, or after $60 \mathrm{~min}$ for gene transfer experiments. The longer time in the latter case was chosen to allow the completion of the transfer. For transmission electron microscopy, the cells were grown on $2 \%$ YEPD agar plates overnight and then after amiodarone treatment were washed and fixed. All incubations were performed at room temperature.

The cells were stained either with propidium iodide (PI, Sigma Chemical) or with the DNA-specific fluorochrome 4', 6'-diamidino-2-phenylindole (DAPI, Sigma Chemical). For PI staining of cultures, cells were pelleted by centrifugation for $5 \mathrm{~min}$ at $400 \mathrm{~g}$, the supernatant was discarded, and the cells were resuspended in PI solution $(25 \mu \mathrm{g} / \mathrm{ml}$ in PBS) for $20 \mathrm{~min}$ at room temperature (Green et al. 1999). DAPI staining was performed for $10 \mathrm{~min}$, the concentration of the dye being $300 \mu \mathrm{M}$ (Morishita and Engebrecht 2005). The cells were grown to logarithmic phase on YPD medium, transferred into water, stained with $1 \mathrm{mM}$ Mitotracker Red for $5 \mathrm{~min}$, washed twice with water, and treated with either $0.4 \%$ DMSO (control), or $80 \mu \mathrm{M}$ amiodarone. Cells stained with MitoTracker Red and PI and were visualized with an upright Olympus BX51 microscope and U-MNG2 filter set (excitation 530-570 nm, 570-nm beam splitter filter, emission $>590 \mathrm{~nm}$ ). Cells stained with DAPI were visualized with a U-MNU2 filter set (excitation 360-370 nm, 400-nm beam splitter filter, emission $>420 \mathrm{~nm}$ ).

\section{Transmission electron microscopy}

To facilitate cell-to-cell contacts and to secure the formed channels, colonies were treated with $80 \mu \mathrm{M}$ amiodarone in DMSO to a final concentration $0.4 \%$ directly on the agar plates for $15 \mathrm{~min}$. After that, the amiodarone was removed by washing the agar plates, and the colonies were covered by liquid agar at the ambient temperature. Then the agar was cut into blocks. Small and thin agar blocks containing colonies treated (experimental samples) or untreated with amiodarone and treated with DMSO instead, final concentration $0.4 \%$ (control sample), were washed twice in $0.1 \mathrm{M}$ cacodylate buffer $(\mathrm{pH}$ 7.2). After embedding sections in the resin, we examined the cells comprising the colony. Fixation was performed in two steps: prefixation twice for $1 \mathrm{~h}$ in $5 \%$ glutaraldehyde (with adding of $5 \% \mathrm{DMSO} \mathrm{v} / \mathrm{v}$ and $1.0 \mathrm{M}$ sucrose) and post-fixation in $1.0 \% \mathrm{OsO}_{4}$ in cacodylate buffer $\mathrm{pH}$ 7.2 overnight at $4{ }^{\circ} \mathrm{C}$. The blocks were dehydrated in a series of alcohol solutions with increasing concentrations $(30,50,70,80,96$, and $100 \%)$, and then the blocks were embedded in araldite (Fluka). Ultrathin sections were prepared using an LKB 4800 ultramicrotome (LKB-Produkter, Sweden), contrasted with lead citrate in accordance with Reynolds (1963), and analyzed (Carl Zeiss electron microscope LEO912 AB, Germany, accelerating voltage $100 \mathrm{kV}$ ).

\section{Gene transfer experiments}

Two milliliters of m14 (leu2ade2URA3) and u23-25 (leu$2 u r a 3 A D E 2)$ cells $[\mathrm{OD} 600=0.2]$ were mixed and $80 \mu \mathrm{M}$ amiodarone in DMSO was added to the mixture. After $5 \mathrm{~min}$, the cells were centrifuged to facilitate cell-tocell contacts and then incubated for $1 \mathrm{~h}$. The cells were then resuspended and transferred onto YNB plates lacking adenine and uracil. The control cells were treated in the same way but with addition of DMSO instead of amiodarone.

\section{Flow cytometry}

DNA content was determined according to (Epstein and Cross 1992) with one modification: treatment with RNAse was 20 min only because longer incubations reduced the signal. Briefly, the cells were fixed in $70 \%$ ethanol overnight at $4{ }^{\circ} \mathrm{C}$, then digested with $1 \mathrm{mg} /$ $\mathrm{ml}$ RNAse (in $50 \mathrm{mM}$ Tris- $\mathrm{HCl}(\mathrm{pH} 8)$ for $20 \mathrm{~min}$ and stained with $50 \mu \mathrm{g} / \mathrm{ml}$ propidium iodide (in $180 \mathrm{mM}$ Tris- $\mathrm{HCl}$ (pH 7.5), $190 \mathrm{mM} \mathrm{NaCl}, 70 \mathrm{mM} \mathrm{MgCl}_{2}$, overnight at $4{ }^{\circ} \mathrm{C}$ ). Prior to measurements, the cells were ultrasonicated. Fluorescence and forward-angle light scattering were measured using a Becton-Dickinson FACScan instrument. In each experiment 10,000 cells were examined. 


\section{Abbreviations}

CW: cell wall; DAPI: 6'-diamidino-2-phenylindole; DIC: differential interference contrast; EM: electron microscopy; G: glucan layer; MP: mannoprotein layer; PI: propidium iodide; YNB: yeast nitrogen base; YEPD: yeast extract, pepton, D-glucose.

\section{Authors' contributions}

TSK, FFS, and SSS performed fluorescence microscopy experiments, designed the experimental plan, analyzed results, and wrote the manuscript; SSS performed FACS experiments; TSK and IOS performed electron microscopy experiments; DPV participated in the electron- and fluorescence-microscopy experiments. All authors read and approved the final manuscript.

\section{Author details}

1 Department of Molecular Biology, Faculty of Biology, Lomonosov Moscow State University, 1-12 Leninskie Gory, Moscow 119992, Russia. ${ }^{2}$ Belozersky Research Institute of Physico-Chemical Biology, Lomonosov Moscow State University, 1-40 Leninskie Gory, Moscow 119992, Russia. ${ }^{3}$ Department of Bioengineering, Faculty of Biology, Lomonosov Moscow State University, 1-12 Leninskie Gory, Moscow 119992, Russia. ${ }^{4}$ Present Address: Institute for Molecular Bioscience, University of Queensland, Queensland, Australia.

\section{Acknowledgements}

The experiments presented in Figs. 1a, b, 3, and 4 were supported by the Russian Science Foundation grant 14-14-00181, the experiments presented in Figs. 1c, d, 2a1, b- $d$ were supported by grant 14-04-01187 from the Russian Foundation for Basic Research and the experiments presented in Fig. 2a2, e were supported by a grant of the Russian Scientific Fund (contract \# 14-5000029). We would like to thank the Center for collective use of MSU for the opportunity to work with an electron microscope.

\section{Compliance with ethical guidelines}

\section{Competing interests}

The authors declare that they have no competing interests.

Received: 4 December 2014 Accepted: 27 July 2015

Published online: 26 August 2015

\section{References}

Agaphonov M, Romanova N, Sokolov S, lline A, Kalebina T, Gellissen G, Ter-Avanesyan M (2005) Defect of vacuolar protein sorting stimulates proteolytic processing of human urokinase-type plasminogen activator in the yeast Hansenula polymorpha. FEMS Yeast Res 5(11):1029-1035

Cabib E, Farkas V, Kosík O, Blanco N, Arroyo J, McPhie P (2008) Assembly of the yeast cell wall. Crh1 $p$ and Crh2p act as transglycosylases in vivo and in vitro. J Biol Chem 283(44):29859-29872

Courchesne WE, Tunc M, Liao S (2009) Amiodarone induces stress responses and calcium flux mediated by the cell wall in Saccharomyces cerevisiae. Can J Microbiol 55(3):288-303

de Souza Pereira R, Geibel J (1999) Direct observation of oxidative stress on the cell wall of Saccharomyces cerevisiae strains with atomic force microscopy. Mol Cell Biochem 201(1-2):17-24

Dmitriev V, Tsiomenko A, Kulaev I, Fikhte B (1980) A cyto-biochemical study of the "canal" formation in the yeast cell wall. Eur J Appl Microbiol 9(3):211-216

Epstein CB, Cross FR (1992) CLB5: a novel B cyclin from budding yeast with a role in S phase. Genes Dev 6(9):1695-1706
Gamarra S, Rocha EM, Zhang YQ, Park S, Rao R, Perlin DS (2010) Mechanism of the synergistic effect of amiodarone and fluconazole in Candida albicans. Antimicrob Agents Chemother 54(5):1753-1761

Green LJ, Marder P, Mann LL, Chio L, Current WL (1999) LY303366 exhibits rapid and potent fungicidal activity in flow cytometric assays of yeast viability. Antimicrob Agents Chemother 43(4):830-835

Klis FM, Mol P, Hellingwerf K, Brul S (2002) Dynamics of cell wall structure in Saccharomyces cerevisiae. FEMS Microbiol Rev 26(3):239-256

Koren A (2006) Is Saccharomyces cerevisiae apoptotic cell death associated with gene transfer? JUBMB Life 58(4):203-207

Lesage G, Bussey H (2006) Cell wall assembly in Saccharomyces cerevisiae. Microbiol Mol Biol Rev 70(2):317-343

Lyamzaev KG, Nepryakhina OK, Saprunova VB, Bakeeva LE, Pletjushkina OY, Chernyak BV, Skulachev VP (2008) Novel mechanism of elimination of malfunctioning mitochondria (mitoptosis): formation of mitoptotic bodies and extrusion of mitochondrial material from the cell. Biochim Biophys Acta 1777(7-8):817-825

Morishita M, Engebrecht J (2005) End3p-mediated endocytosis is required for spore wall formation in Saccharomyces cerevisiae. Genetics 170(4):1561-1574

Orlean P (2012) Architecture and biosynthesis of the Saccharomyces cerevisiae cell wall. Genetics 192(3):775-818

Ozhovan SM, Knorre DA, Severin FF, Bakeeva LE (2009) Yeast cell ultrastructure after amiodarone treatment. Tsitologiia 51(11):911-916

Pozniakovsky Al, Knorre DA, Markova OV, Hyman AA, Skulachev VP, Severin FF (2005) Role of mitochondria in the pheromone- and amiodaroneinduced programmed death of yeast. J Cell Biol 168(2):257-269

Reynolds ES (1963) The use of lead citrate at high pH as an electron-opaque stain in electron microscopy. J Cell Biol 17:208-212

Sestak S, Hagen I, Tanner W, Strahl S (2004) Scw10p, a cell-wall glucanase/ transglucosidase important for cell-wall stability in Saccharomyces cerevisiae. Microbiology 150(Pt 10):3197-3208

Smits GJ, Kapteyn JC, van den Ende H, Klis FM (1999) Cell wall dynamics in yeast. Curr Opin Microbiol 2(4):348-352

Sokolov S, Knorre D, Smirnova E, Markova O, Pozniakovsky A, Skulachev V, Severin F (2006) Ysp2 mediates death of yeast induced by amiodarone or intracellular acidification. Biochim Biophys Acta 1757(9-10):1366-1370

Suh SO, Zhou JJ (2010) Methylotrophic yeasts near Ogataea (Hansenula) polymorpha: a proposal of Ogataea angusta comb. nov. and Candida parapolymorpha sp. nov. FEMS Yeast Res 10(5):631-638

Teparić R, Mrsa V (2013) Proteins involved in building, maintaining and remodeling of yeast cell walls. Curr Genet 59(4):171-185

Yamada Y, Maeda K, Mikata K (1994) The phylogenetic relationships of the hatshaped ascospore-forming, nitrate-assimilating Pichia species, formerly classified in the genus Hansenula Sydow et Sydow, based on the partial sequences of $18 \mathrm{~S}$ and $26 \mathrm{~S}$ ribosomal RNAs (Saccharomycetaceae): the proposals of three new genera, Ogataea, Kuraishia, and Nakazawaea. Biosci Biotechnol Biochem 58(7):1245-1257

\section{Submit your manuscript to a SpringerOpen ${ }^{\circ}$ journal and benefit from:}

- Convenient online submission

- Rigorous peer review

- Immediate publication on acceptance

- Open access: articles freely available online

- High visibility within the field

- Retaining the copyright to your article

Submit your next manuscript at $\boldsymbol{~ s p r i n g e r o p e n . c o m ~}$ 